of the central retinal, then to a smaller branch and so on till it broke up into a veritable net-work and could trace back a vein from this net-work to the main veins. In three separate parts of the fundus of each eye, I could see with absolute distinctness, beyond any possibility of mistake, an anastomosis between two small arteries. There were two such anastomoses between branches of the inferior and temporal retinal arteries and one such anastomosis between branches of the inferior and nasal retinal arteries.

I could find no such anastomosis in the upper half of the fundus in either eye. From first to last the media remained absolutely clear and I never could detect the smallest trace of a retinal haemorrhage at any period.

On referring to Fuchs' Text Book of Ophthalmology (fifth . edition, pp. 580-581), I found the following:-“Very rarely in young diabetics, especially when nearing death, retinal lipaemia is found, i.e., a condition in which on account of the large amount of fat in the blood, the retinal vessels appear reddish white or pure white." This statement is by Duane.

Such a condition was not found in the case described above. The blood examination failed to reveal any marked divergence from the normal, and its colour, when drawn from a pricked finger, was quite satisfactory. Further, the filling in of the sulcus between the walls of the larger vessels and the retina showed the presence of an exudative coating.

\title{
ANNOTATION
}

\section{Blindness in Trinidad and Tobago}

A valuable attempt, admittedly incomplete, has been made by Mr. Métevier towards the correct estimation and prophylaxis of blindness in Trinidad and Tobago. As a foundation for further work in these islands the report, which will be laid before the Legislative Council, is admirable, and some interesting facts are recorded in it. In this colony the question as to whether a person is blind or not has up to the present been largely decided by the Committee of the Institute for the Blind. The granting of Poor Relief last year has brought the condition of economic blindness in some cases of unemployment and indigence before the Inspector for Poor Relief. No further state action for dealing specifically with the blind has been taken; but, acting on the suggestion of Mr. and Mrs. Holt Mather, of New York, the Committee of the Institute of the Blind has had under consideration the preparation of a census of the blind in this colony. Mr. Metevier has examined the cases in the various institutions, and has added details of 53 patients seen in private between January 1, 1931 and April 30, 1932. 
The population of Trinidad and Tobago in 1931 amounted to 412,783 , of whom 823 were blind, giving a figure of $199 \cdot 3$ per 100,000 . Tobago, in the same year, with a population of 25,352 , had 56 blind persons.

The state census has, up till now, given too low a figure for the blind in this colony. Thus in 1931 the blind returns in the census for inmates of the House of Refuge were 34: (male 23, females 11). $\mathrm{Mr}$. Métevier's examination of the inmates disclosed a figure of 63 , with 41 males, and 22 females. The same under-estimation is apparent in the figures for the leper settlement ; 10 blind according to the census returns, and 15 in those of Metevier.

The definition of blindness in this report is that of the Blind Persons' Act 1920 of this country for adults; and in the case of children, if a child's sight is so defective that he or she cannot read the ordinary school books without danger to sight, that child may be regarded as blind for educational purposes.

Of the 15 blind lepers, the blindness in every case but one was directly due to leprosy. The one exception was due to uncomplicated senile cataract in the only remaining percipient eye, the other being blind from complications of anaesthetic leprosy. This case is suitable for operation, and Métevier notes that lepers are reported to stand eye operations very well.

The figures of 194 cases of blindness which form the basis of this report give the following diseases among the important causes: syphilis, 45 cases; primary glaucoma, 38 ; primary senile cataract, 20 ; adult ophthalmia, 11; ophthalmia neonatorum, 4; congenital cases, 5; leprosy, 14; the rest, 57. Thus syphilis and glaucoma are a predominant factor in this colony; focal sepsis and vitamin deficiency are aggravating factors; trachoma has not been found to be a cause of blindness, and occupational causes are practically nonexistant; no cases of blindness due to myopia have been recorded. The figures for ophthalmia neonatorum are low, but those of purulent ophthalmia of adults are higher than one would have expected. The subject of optic nerve disease is important and demands further investigation. An unusual series of cases occcurring in five members of a family has been noted. The census figures for 1931 show an increase in blindness of 46 per 100,000 of total population; when compared with those of 1921 .

The author is insistent on the need for prophylaxis and the system of registration which obtains in Great Britain. An educational campaign is one method of inducing people to seek medical advice, for the rustic of Trinidad apparently has a fervid belief in the efficacy of simple lotions for glaucoma, and after weeks of such treatment may possibly visit an optician.

It is to be hoped that ophthalmic surgeons who practise in other Crown Colonies will copy Mr. Métevier in his task, and thus leảd to a general amelioration of the figures for the blind population of the Empire. The author deserves unstinted praise for his work. 